\title{
Extracción de polisacáridos sulfatados a partir del tegumento del pepino de mar Pattalus mollis
}

\author{
Extraction of sulfated polysaccharides from the tegument of sea cucumber \\ Pattalus mollis
}

\author{
Diego Gonzáles ${ }^{1}$, Carlos Pariona ${ }^{1}$, Pablo Londoñe ${ }^{1,2}$
}

\section{Resumen}

Los polisacáridos aislados de Pattalus mollis (PPM) fueron obtenidos por el método de hidrolisis enzimática y por la precipitación con etanol. Se realizó un análisis de componentes el cual consistió en la determinación del contenido de sulfatos, azucares totales y proteínas totales por métodos convencionales. El objetivo de este trabajo fue obtener los polisacáridos por hidrolisis enzimática. Se utilizó la enzima papaína para romper las uniones peptídicas y el etanol para precipitar los polisacáridos. El contenido de sulfatos, azucares totales y proteínas cual fue $2.36,2.83$ y $22.3 \%$, respectivamente.

Palabras clave: polisacáridos; hidrolisis enzimática; sulfatos; azucares totales; proteínas totales

\section{AbSTRaCT}

Polysaccharides isolated from Pattalus mollis (PPM) were obtained by the method of enzymatic hydrolysis and by precipitation with ethanol. A component analysis was carried out, which consisted in the determination of the content of sulfates, total sugars and total proteins by conventional methods. The objective of this study was to obtain the polysaccharides by enzymatic hydrolysis. The enzyme papain was used to break peptide bonds and ethanol to precipitate polysaccharides. The content of sulfates, total sugars and proteins was $2.36,2.83$ and $22.3 \%$, respectively.

Key words: polysaccharides; enzymatic hydrolysis; sulfates; total sugars; total proteins

\footnotetext{
${ }^{1}$ Laboratorio de Biotecnología, Dirección de Investigación, Desarrollo, Innovación y Transferencia Tecnológica, Instituto Tecnológico de la Producción, Ministerio de la Producción, Callao, Perú

${ }^{2}$ E-mail: plondone@itp.gob.pe
}

Recibido: 19 de diciembre de 2018

Aceptado para publicación: 3 de julio de 2019 
La clase Holothuroidea abarca más de 1500 especies de pepino de mar (Sulub y Perera, 2011). Algunas de estas especies son comestibles en China y otros países asiáticos, además de ser utilizados en medicina tradicional (Amr et al., 2013). En el Perú, una de las especies más abundantes de estos invertebrados marinos es Pattalus mollis (Hooker et al., 2013).

Se ha reportado que los polisacáridos, generalmente los del tipo sulfatados, procedentes de pepino de mar tienen diversas actividades biológicas. Para el aislamiento de los polisacáridos se dispone de varias técnicas de extracción, como digestión enzimática, precipitando con etanol, fermentación, digestión proteolítica, hidrólisis ácida, o la combinación de algunos de estos tratamientos (Jeon et al., 2008). Los métodos enzimáticos permiten el rompimiento de las cadenas de proteínas, transformándolas en péptidos, debido a que muchas de estas moléculas que se encuentra unidas a los polisacáridos son llamadas heteropolisacáridos (Borbar et al., 2011). Además, el uso del etanol permite que los polisacáridos precipiten debido a que la mayoría son insolubles en solventes orgánicos.

Los polisacáridos son utilizados en la industria alimentaria como aditivos, así como en la elaboración de nuevos productos que contribuyen a la salud; incluso se usan para elaborar películas comestibles (Yu et al., 2018). Por esta razón se buscan nuevas fuentes naturales de polisacáridos, de allí que el objetivo de este trabajo fue obtener polisacáridos de Pattalus mollis (PPM) por hidrolisis enzimática y precipitación con etanol, así como determinar el contenido de sulfatos, azucares y proteínas que pueden ser una nueva fuente natural beneficiosa.

\section{Muestreo y Muestras}

En marzo de 2017 se colectaron pepinos de mar ( $P$. mollis), provenientes de las costas de Chuncho, frente al puerto de Pucusana, Lima (12²7'58.1' S 76²4'27.9'" O). El muestreo se realizó por buceo a profundidades de 2 a $3 \mathrm{~m}$. Las muestras fueron llevadas a los laboratorios del Instituto Tecnológico de la Producción(ITP), Callao, Perú, para limpiar y eliminar los residuos orgánicos adheridos al cuerpo. Los pepinos de mar fueron diseccionados separando la pared corporal (tegumento) del tracto digestivo (vísceras) y aparato reproductor (gónada) para ser almacenados a $-20^{\circ} \mathrm{C}$ hasta su uso.

Se molió hasta formar una pasta homogénea y el tegumento fue secado a $60{ }^{\circ} \mathrm{C}$ por $20 \mathrm{~h}$ para eliminar el mayor contenido de agua (5-10\%). Para eliminar los lípidos de la muestra en polvo se preparó una solución de metanol (Tedia, Ohio, USA) y cloroformo (Merck, Darmstadt, Alemania) (1:1). En un vaso de precipitado se añadió $200 \mathrm{~g}$ de muestra seca en relación de 1:3(p/v), se agitó a $6000 \mathrm{rpm}$ a $25^{\circ} \mathrm{C}$ en un agitador magnético (DLAB Scientific, Beijing, China) por $1 \mathrm{~h}$ en oscuridad. Esto fue repetido cuatro veces para retirar el mayor contenido de lípidos de la muestra seca. Luego se realizó el análisis proximal según AOAC (1997).

\section{Hidrolisis Enzimática}

A partir de la muestra en polvo seca y sin lípidos del tegumento, se realizó una hidrolisis enzimática utilizando el método de Sheng et al. (2007) con algunas modificaciones. Brevemente, en un vaso de precipitado se pesó $20 \mathrm{~g}$ de matriz y se añadió $300 \mathrm{ml}$ de $0.1 \mathrm{M}$ de buffer acetato de sodio (pH 6.6), además de contener $5 \mathrm{mM}$ de EDTA 
(Calbiochen, Massachusetts, USA), $5 \mathrm{mM}$ de cisteína (Merck, Darmstadt, Alemania) y 5\% de papaína (Merck, Darmstadt, Alemania). La solución fue llevada a un agitador magnético (Agimatic, Barcelona, España) por 30 $\mathrm{min}$, para luego incubar a $60^{\circ} \mathrm{C}$ por $24 \mathrm{~h}(\mathrm{Fi}-$ gura 1). Después se retiró el hidrolizado de la estufa y se centrifugó a $4025 \mathrm{~g}$ por $20 \mathrm{~min}$ a $25^{\circ} \mathrm{C}$, se descartó el precipitado y se inactivó la enzima a $90^{\circ} \mathrm{C}$ por $5 \mathrm{~min}$, para enfriar a $4{ }^{\circ} \mathrm{C}$ $\mathrm{y}$ filtro mediante papel Whatman \#1 para eliminar el residuo que podría haber quedado en la inactivación. El sobrenadante se almacenó en refrigeración a $4{ }^{\circ} \mathrm{C}$.

\section{Obtención de Polisacáridos}

Luego de la inactivación enzimática, se agregó al sobrenadante una solución de etanol (Merck, Darmstadt, Alemania) al 90\% en un relación de 1:3 (v/v) (Figura 2) y se colocó en un sonicador (Symphony, Massachusetts, USA) por $3 \mathrm{~min}$, para incubar por $24 \mathrm{~h} \mathrm{a} 4^{\circ} \mathrm{C}$. Finalizado el tiempo de incubación, el polisacárido se decantó para una mayor deshidratación, se centrifugó a $4025 \mathrm{~g}$ por 20 min a $4{ }^{\circ} \mathrm{C}$, se retiró el sobrenadante, se mezclaron todos los pellets obtenidos por el centrifugado, y deshidrató mediante lavados con acetona (Merck, Darmstadt, Alemania) al 100\%. Se añadió $40 \mathrm{ml}$ de acetona e inmediatamente se centrifugó a las condiciones indicadas anteriormente. Se retiró la acetona mediante evaporación dentro de una campana extractora por $6 \mathrm{~h}$ para obtener polisacáridos sin resto de solventes orgánicos. Luego se almacenó dentro de un desecador (conteniendo silicagel) para una deshidratación total, obteniéndose polvo de color morado. El flujo de la obtención de polisacáridos a partir de tegumento se puede apreciar en la Figura 1.

\section{Análisis de Componentes}

Se realizó un análisis de los componentes de PPM. Para ello se determinó el contenido de sulfato (Therho y Hartiala, 1970), azucares totales (Dubois et al., 1956) y proteínas solubles (Lowry et al., 1951).

\section{Resultados}

Los resultados del análisis proximal de la muestra seca y sin lípidos se muestran en la Figura 2. Se obtuvo 25\% de rendimiento $(2.45 \mathrm{~g})$ de polisacáridos a partir de la muestra de $20 \mathrm{~g}$ de tegumento.

La determinación de sulfatos, azucares totales y proteínas totales fueron calculadas de acuerdo con las curvas mostradas en la Figura 3. Los resultados de la caracterización química del extracto crudo del tegumento de $P$. mollis muestran $2.83 \%$ de azucares totales, $22.3 \%$ de proteínas totales y $2.36 \%$ de sulfato (Cuadro 1)

\section{Discusión}

La hidrolisis enzimática se usa comúnmente para desproteinizar los extractos de polisacáridos animales. La papaína es una proteasa que se usa en la preparación de polisacáridos, como en el erizo de mar (Liu et al., 2008). Por otro lado, los polisacáridos de origen animal contienen altos niveles de proteínas, que generalmente dificulta el análisis de la composición química. En este estudio se usó la hidrolisis enzimática y la precipitación con etanol para obtener los PPM (Cuadro 1).

Algunos estudios indican que los polisacáridos que tienen grupos sulfatos en su composición pueden presentar actividades biológicas y farmacológicas de interés. Liu et al. (2012) reportaron que el extracto de polisacáridos de Apostichopus japonicus (PAJ) presentó $15.74 \%$ de sulfato, $64.21 \%$ de azucares totales y $10.03 \%$ de proteínas totales; es decir, una mayor cantidad mayor de azucares totales que en Pattalus mollis, los cual puede indicar una mayor probabilidad de actividad biológica a diferencia de PPM. Estas diferencias en los contenidos de sulfato y azucares totales puede deberse a la salinidad del agua, pues aquella que se en- 


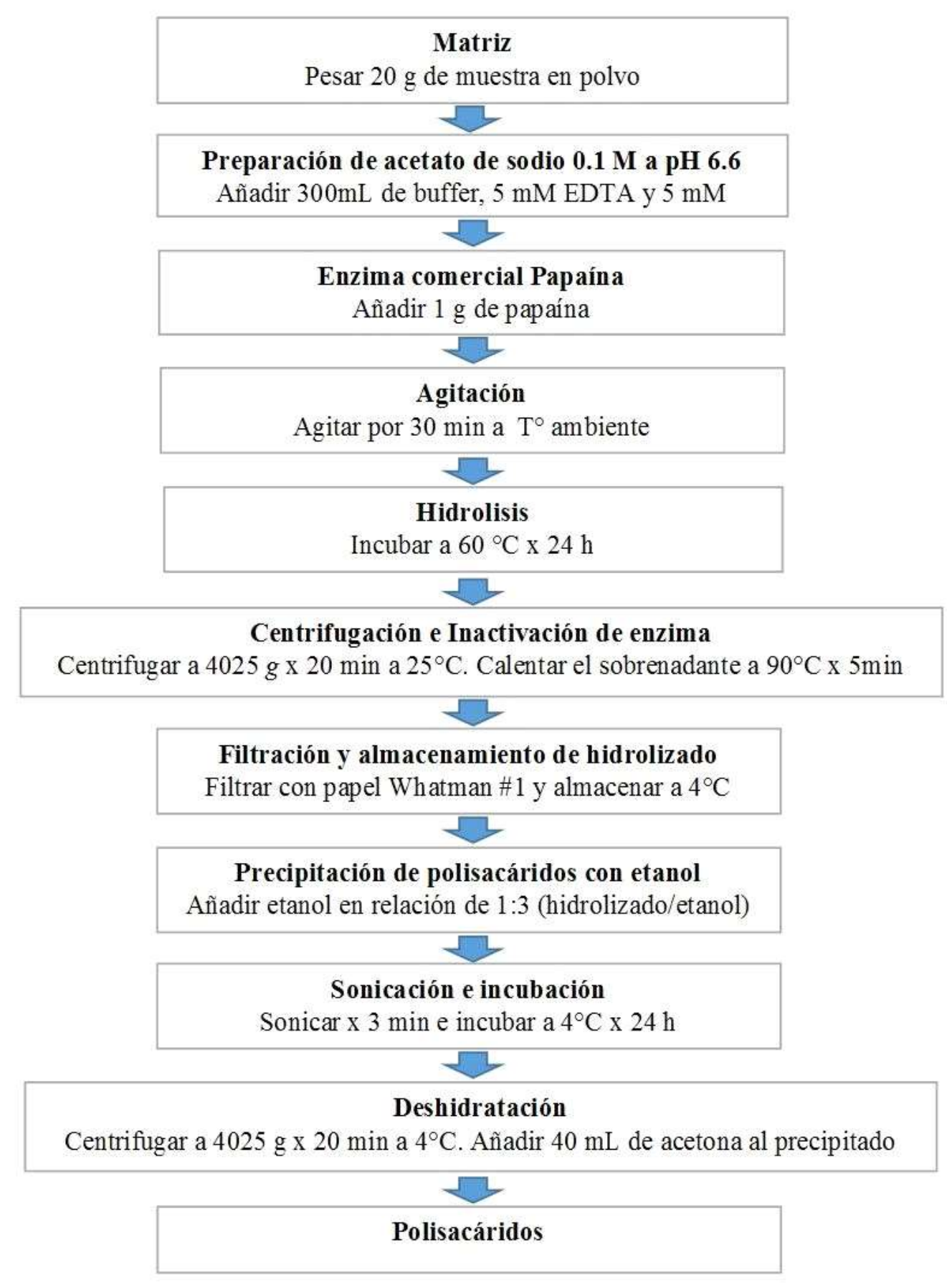

Figura 1. Diagrama de flujo del proceso de obtención de los polisacáridos 


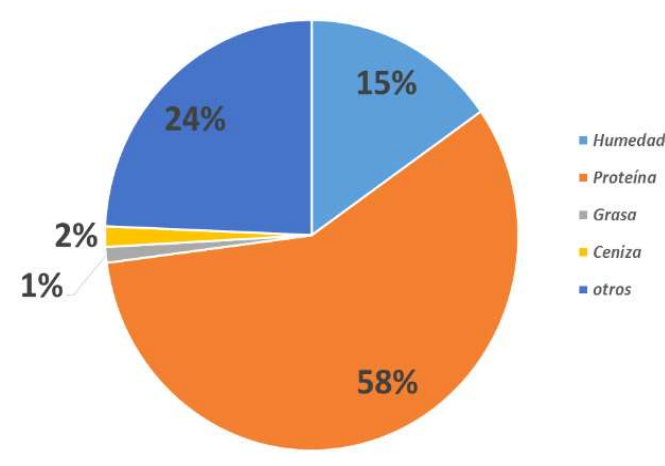

Figura 2. Análisis proximal de la muestra seca y sin lípidos del tegumento de Pattalus mollis

cuentra cerca del Ecuador es menos salina que las más alejadas, por ello contiene menos concentraciones de sodio y potasio, moléculas principales para la formación de sales sulfatadas (Shani y Dudley, 2001). Además, los PPM presentaron aproximadamente el doble de contenido de proteínas totales, lo cual permite presumir que el PPM presenta una estructura mucho más compleja que los PAJ, ya que el contenido de proteínas unido a carbohidratos dificulta el análisis químico.

Rong-An et al. (2017) reportaron que los polisacáridos obtenidos de Stichopus japonicus (PSJ) presentan $56.6 \%$ de proteína, siendo estas cantidades mayores a las del presente estudio, posiblemente debido a que utilizaron el método de Sevag et al. (1938) para eliminar las proteínas libres, donde no se utiliza enzimas para el rompimiento de las cadenas peptídicas y solo precipitaron los polisacáridos con etanol. Por otro lado, el contenido de sulfatos de PSJ fue $16 \%$ a diferencia de PPM que fue de $2.36 \%$, lo cual puede estar relacionado a la presencia del fenómeno de El Niño de 2017, donde el grado de salinidad estuvo entre 30-34 ups y la temperatura entre 25 y $28{ }^{\circ} \mathrm{C}$, pudiendo haber afectado a las especies marinas.

En otro estudio, Li et al. (2016) determinaron $20.7 \%$ de contenido de sulfato en el extracto de polisacáridos obtenidos de Holothuria fuscogliva, siendo mayor la cantidad de polisacáridos sulfatados respecto a P. mollis. Ambas especies son organismos bentónicos; sin embargo, las características del hábitat no son iguales, de allí que factores del agua como $\mathrm{pH}$, salinidad y temperatura, entre otros, hace variar los contenidos de sulfatos (Morales, 2017).

\section{Conclusiones}

Los polisacáridos obtenidos por hidrolisis enzimática y precipitación con etanol de Pattalus mollis resultaron ser polisacáridos complejos, debido a que presentaron un contenido de sulfatos, azucares y proteínas, demostrando que son del tipo heteropolisácaridos. Los análisis de componentes pueden sugerir que los PPM presentan actividades biológicas de gran importancia.

Cuadro 1. Análisis de componentes de polisacáridos del pepino de mar Pattalus mollis

\begin{tabular}{lcccc}
\hline Analito & Promedio & $\mathrm{DS}^{\mathrm{a}}$ & $\mathrm{CV}^{\mathrm{b}}$ & $\%$ \\
\hline Sulfatos & $0.0236^{1}$ & 0.0001 & 0.24 & 2.36 \\
Azucares totales & $0.0283^{2}$ & 0.0006 & 2.01 & 2.83 \\
Proteínas totales & $0.223^{3}$ & 0.0005 & 0.23 & 22.3 \\
\hline
\end{tabular}

a Desviación estándar; ${ }^{b}$ Coeficiente de variación

${ }^{1} \mu \mathrm{g} \mathrm{SO}{ }_{4}^{-} / \mu \mathrm{g}$ de muestra; ${ }^{2} \mu \mathrm{g}$ fucosa/ $\mu \mathrm{g}$ de muestra; ${ }^{3} \mu \mathrm{g}$ albúmina/ $\mu \mathrm{g}$ de muestra 

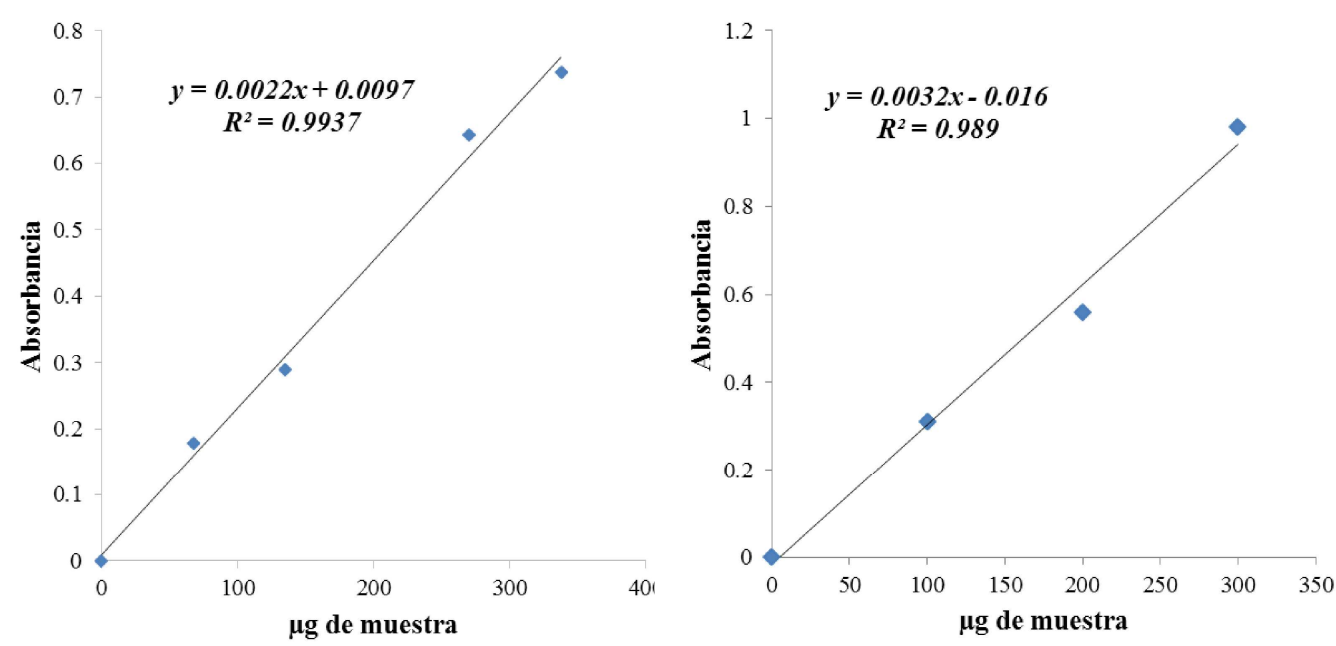

(a)

(b)

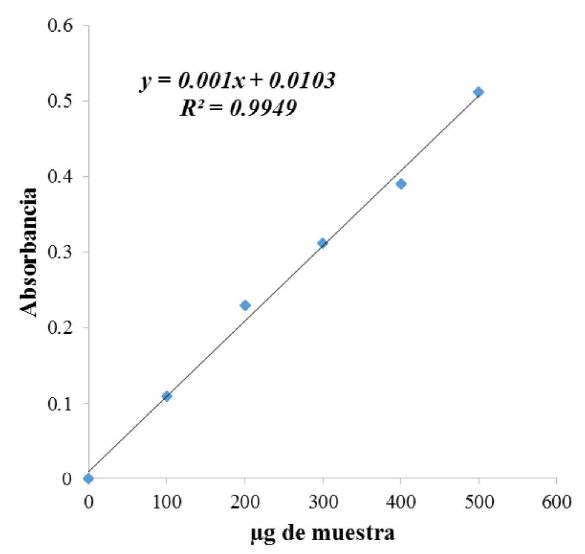

(c)

Figura 3. Curvas de calibración con sus respectivas ecuaciones utilizadas para determinar sulfatos, azucares totales y proteínas totales mediante el material de referencia (a) ion sulfato, (b) fucosa y (c) albúmina, respectivamente

\section{Agradecimientos}

Se agradece al Programa Nacional de Innovación para la Competitividad y Productividad (Innóvate Perú) por financiar y permitir el desarrollo de este trabajo en el marco Convenio N. ${ }^{\circ} 302$ - INNOVATEPERUPIAP-2015.

\section{Literatura Citada}

1. Amr YE, Mahmoud MS, Amel AS, Khaled HE, Elham AB. 2013. Bioactivecompounds, antioxidant- potential, and hepatoprotective activity of sea cucumber (Holothuria atra) against thioacetamide intoxication in rats. Nutri 29: 258-267, doi: 10.1016/ j.nut.2012.06.004

2. AOAC. 1997. Association of Official Analytical Chemists International Official Methods of Analysis. 16th Edition, AOAC, Arlington.

3. Borbar S, Anwar F, Saari N. 2011. High-value componets and bioactives from sea cucumbers for functional foods. Mar Drugs 9(10): 1761-1805, doi: 10.3390/md9101761. 
4. Dubois M, Gilles KA, Hamilton JK, Rebers PA, Smith F. 1956. Colorimetric method for determination of sugars and related substances. Anal Chem 28: 81798184, doi: 10.1021/ac60111a017

5. Hooker Y, Prieto-Rios E, Solis-Marín FA. 2013. Echinoderms of Perú. In Echinoderm research and diversity in Latin America. Lima, Perú. p 277-299, doi: 10.1007/978-3-642-20051-9-8.

6. Jeon Y, Jee Y, Lee J. 2008. Anticoagulant activity of sulfated polysaccharidae isolated from fermented brown seaweed Sargassum fulvellum. J Appl Phys 20: 67-74, doi: 10.1007/ s10811-007-9182-7.

7. Liu CH, Xi T, Lin QX, Xing YY, Ye L, Luo $X G$. 2008. Immunomodulatory activity of polysaccharide isolated from Strongylocentrotus nudus eggs. Inter Immunol 8: 1835-1841, doi: 10.1016/ j.intimp.2008.09.005.

8. Liu X, Sun Z, Zhang M, Meng X, Xia $X$, Yuan W. 2012. Antioxidant and antihyperlipidemic activities of polysaccharides from sea cucumber Apostichopus japonicus. Carbohy Polym 90(4): 1664-1670, doi: 10.1016/ j.carbpol.2012.07.047.

9. Li R, Yu H, Yue Y, Liu S, Xing R, Chen $X$. 2016. Sulfated polysaccharides with antioxidant and anticoagulant activity from the sea cucumber Holothuria fuscogliva. Chin J Oceanol Limn 34 (6): 432-436, doi: 10.1007/s00343-017-5339-7.

10. Lowry OH, Rosebrough NJ, Farr AL, Randall RJ. 1951. Protein measurement with the Folin phenol reagent. J Biol Chem 193: 265-275.
11. Morales F. 2017. Estudio del efecto de las interacciones del sistema 'agua de mar - cal' en procesamiento de minerales. Santiago de Chile, Chile. 22-24.

12. Rong-An C, Ultoomporn S, SanGuan Y. 2017. Structural characterization of immnuostimulating protein - sulfated fucan complex extracted from the body Wall of a sea cucumber, Stichopus japonicus. Inter J Biol Macro 99: 539548, doi: 10.1016/j.ijbiomac.2017.03.026.

13. Sevag MG, Lackman DB, Smolens J. 1938. The isolation of the components of streptococcal nucleoproteins in serologically active form, J Biol Chem. 124: 425-436.

14. Shani U, Dudley L. 2001. Field studies of crop response to water and salt stress. Soil Sci Soc Am J 65: 1522-1528, doi: 10.2136/sssaj2001.6551522x.

15. Sheng WJ, Xu CH, Zhao QX, Xu J, Li ZJ, Sun Y. 2007. Chemical component analysis of polysaccharides from different sea cucumber. Chin J Mar Drugs 26: 44-49.

16. Sulub AT, Perera AA. 2011. Aprovechamiento del pepino de mar: pesquería potencial para el desarrollo económico y social en la costa norte de la Península de Yucatán. Bioagro 4(2): 17-22.

17. Therho TT, Hartiala K. 1971. Method for determination of the sulfate content of glycosamino glycans. Anal Biochem 41: 471-476, doi: 10.1016/00032697(71)90167-9.

18. Yu Y, Shen M, Song Q, Xie J. 2018. Biological activities and pharmaceutical applications of polysaccharide from natural resources: a review. Carbohydr Polym 183: 91-101. doi: 10.1016/ j.carbpol.2017.12.009 